Hier steht eine Anzeige.

黛 Springer 


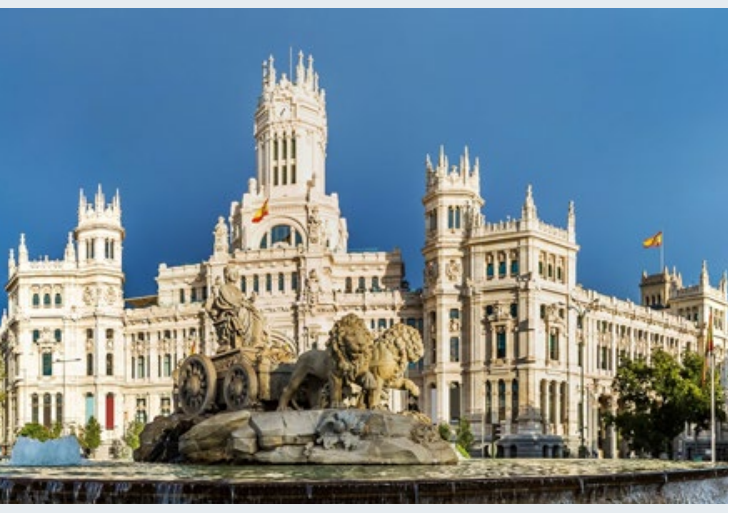

\section{EULAR-Kongress in Madrid}

Fast 14.000 Rheumatologen aus aller Welt haben den Kongress der European League against Rheumatism (EULAR) besucht, der dieses Jahr in Madrid stattfand. Mehr als 355 renommierte Experten stellten aktuelle Studienergebnisse, und neue Entwicklungen ihres Fachgebiets vor.

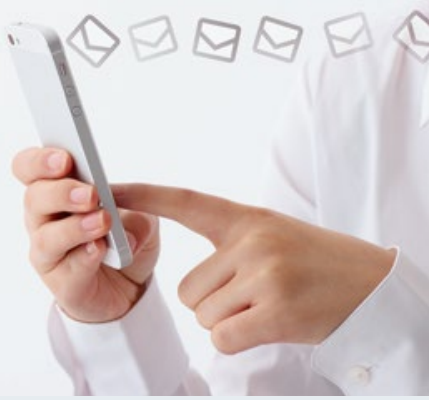

62 Neue Regeln für die E-Signatur

Seit Juli dieses Jahres ermöglicht eine EUVerordnung die elektronische Signatur via Mobiltelefon. Außerdem können Krankenhäuser oder größere Praxiseinheiten digitale Dokumente zentral mit einem elektronischen Siegel rechtssicher machen - vorteilhaft auch für die Archivierung.
IGOST-Mitteilungen

\author{
50 Schmerzspitzen \\ Metamizol - ein gutes Schmerzmittel, aber ... \\ 51 Termine
}

Medizin aktuell

\section{EULAR-Kongress 2017}

\section{Praxis konkret}

\section{Die Spielräume sind begrenzt}

Auch in der GOÄ wachsen die Bäume nicht in den Himmel

56 Intersektorale Versorgung

Finanzielle Fördermittel sollen motivieren

57 Medizinische Versorgungszentren

Gestaltungstipps für Gesellschaftsverträge

60 eIDAS-Verordnung

Neue Regeln für die E-Signatur

62 Mitarbeiterführung

Mit wenigen Bausteinen zu mehr Effizienz im Praxisteam

\section{Prisma}

69 Status quo für den Planet Erde

Ein blasser blauer Punkt

70 Der besondere Fall

MRT entlarvt Riesenzelltumor

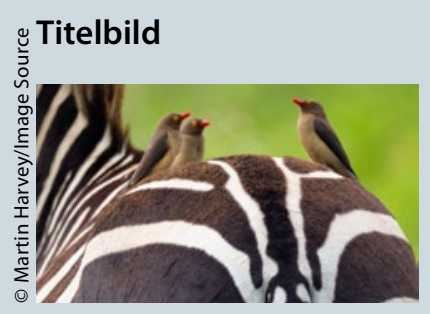

Rotschnabel-Madenhacker auf dem Rücken eines Steppenzebras

\section{Newsletter UPDATE ORTHOPÄDIE}

Alle 14 Tage das Neueste aus Forschung und Berufspolitik bietet Ihnen der Online-Newsletter UPDATE ORTHOPÄDIE. Für diesen kostenlosen Dienst können Sie sich anmelden unter:

www.springermedizin.de/orthopaedieund-rheuma

\section{Rubriken}

03 Editorial

08 Panorama

63 Industrieforum

71 Vorschau

71 Impressum 